Waste and Resource Management Volume 170 Issue WR1

Circular economy in construction: current awareness, challenges and enablers Adams, Osmani, Thorpe and Thornback
Proceedings of the Institution of Civil Engineers

Waste and Resource Management 170 February 2017 Issue WR Pages 15-24 http://dx.doi.org/10.1680/jwarm.16.00011 Paper 1600011

Received 28/06/2016

Published online 20/02/2017

Accepted 23/01/2017

Keywords: recycling \& reuse

waste management \& disposal

Published with permission by the ICE under the CC-BY licence

http://creativecommons.org/licenses/by/4.0/

\title{
Circular economy in construction: current awareness, challenges and enablers
}

Katherine Tebbatt Adams BSC, MSC, LCIWM, PIEMA

$\mathrm{PhD}$ Researcher, School of Civil and Building Engineering, Loughborough University, Loughborough, UK (corresponding author: K.Adams@lboro.ac.uk)

Mohamed Osmani BA, Dip. Arch., MSc, PhD, FHEA

Senior Lecturer, School Civil and Building Engineering, Loughborough

University, Loughborough, UK

\author{
Tony Thorpe CEng, CITP, BSC, MSC, PhD, FICE, FBCS, FCIOB, FRICS, \\ MIMgt \\ Dean, School of Civil and Building Engineering, Loughborough University, \\ Loughborough, UK \\ Jane Thornback BSC, MSC \\ Sustainability Policy Advisor, Construction Products Association, London, UK
}

The application of the concept of circular economy thinking in construction, which is in its infancy, has been largely limited to construction waste minimisation and recycling. Little research on circular economy from a systems perspective including how new business models might enable materials to retain high residual values has been undertaken. Utilising the results from a survey and a follow-up workshop, this paper provides an analysis of an industrywide perspective of circular economy awareness, challenges and enablers. The survey results indicate that while there is industrywide awareness of the concept, clients, designers and subcontractors are the least informed and this is a key challenge for greater adoption. The absence of incentives to design products and buildings for disassembly and reuse at their end of life is a significant challenge. To encourage greater implementation of circular economy principles throughout the supply chain, a clear economic case is paramount, supported by metrics, tools and guidance.

\section{Introduction}

Globally, the human population continues to use more material resources as the population grows and income increases (Behrens et al., 2007; McKinsey Global Institute, 2011). As such, many material resources are likely to become scarier and more costly to use and a large amount of them may be lost for future use (Benton and Hazell, 2013; Defra, 2012; Ecorys, 2012). In the UK, an estimated $37 \%$ of the overall annual materials input, equivalent to $158 \mathrm{Mt}$ is lost (WRAP, 2016). Moving towards a circular economy system provides an opportunity to address this through the reduction of the use of primary materials, protecting material resources and reducing the carbon footprint (EMF and MCK, 2014; Pratt and Lenaghan, 2015). It is also predicted to bring economic benefits, including increases in gross domestic product, net material savings, employment growth, and reduced risk of material price volatility and supply (EEA, 2016; EMF, 2013a; Morgan and Mitchell, 2015). Business benefits may include higher competitiveness, resource security, flexibility and different business models to enable value creation (Lacy et al., 2014; Nasr, 2013; Stahel, 2016). The European Commission, national and regional administrations are developing circular economy policies to bring benefits to the environment and the economy (EC, 2015; LWARB, 2015; SG, 2016). The built environment is an important sector economically, with the construction industry contributing, on average, $5-13 \%$ of the total gross added value (Eurostat, 2015). It is a highly materialintensive sector, consuming between 1.2 and $1.8 \mathrm{Mt}$ of construction materials per annum in Europe (Ecorys, 2014). Construction and demolition activities also generate a large amount of waste, $821 \mathrm{Mt}$ across Europe in 2012, one- third of the total waste generated (Eurostat, 2016). Polices have been developed at the European level to improve significantly the sustainability of the sector (EC, 2011a). While these do not focus on circular economy per se, there is a recognition of the need for the construction industry to become more resource efficient (EC, 2014). The EMF (2015) has estimated that by applying circular economy thinking to the European built environment by 2030, $£ 300$ billion from primary resource benefits, including energy, could be saved.

Much of the recent thinking on circular economy has been on short- and medium-lived consumer products (Benton et al., 2015; EMF, 2013b; Pollard et al., 2016). There is limited research and wide-scale practical applications of circular economy in the modern built environment at the product and the component level. Research to date has largely focused on recycling construction and demolition waste (CDW) with little attention on the reuse of products and there is a subsequent decrease in the materials reclaimed for reuse in the UK (CRWP, 2008; Yuan and Shen, 2011). The prevention of CDW is being considered more so, although more research is needed, especially at the design stages (Osmani et al., 2006). Research on the various aspects of material efficiency within construction, such as the design for deconstruction (DfD) (Kibert, 2003; Tingley, 2012) and achieving the same levels of performance with less material input is mostly limited to a particular material or product type (Allwood et al., 2011). At the building level, buildings can be reused many times (Brandt, 1994; Bullen, 2007), although they are often not designed for this 
purpose (Durmisevic and Yeang, 2009). The aim of this paper is to examine the level of circular economy awareness, challenges and enablers for greater adoption within the UK construction sector.

\section{Circular economy concept and principles}

The term 'circular economy' is becoming increasingly commonplace. Countries such as China and Germany have used the term within their legislation, although the emphasis can vary (Benton, 2015). Waste avoidance and closed-loop recycling are the key components within the German legislation (Bilitewski, 2012), while in the Chinese policy, the term is directed at ecodesign, cleaner production and eco-industrial parks and networks to create a recycling-oriented society (Geng et al., 2012).

Various definitions of the circular economy have been developed, with largely similar principles derived from a number of often interlinked schools of thought, as illustrated in Table 1. Common elements include eliminating the concept of waste and maximising the value of materials (EC, 2015; EMF, 2013a; WRAP, 2016). The EMF (2013a) uses the term 'restorative and regenerative by design', emphasising systems thinking and the need to design out negative externalities. Concern has been raised on the lack of an accepted definition which is seen as a challenge to its uptake (Cossu and Williams, 2015; Preston, 2012; ZWS, 2015). This is compounded by the work being undertaken by various organisations to drive the circular economy forward resulting in the term evolving and the boundaries constantly shifting (Benton and Hazell, 2013; CPA, 2016; ISWA, 2015; MPA, 2016; WEF, 2015). There has been a tendency to interpret circular economy as another recycling or sustainability initiative (Chamberlin et al., 2013).

\section{Circular economy in the built environment}

There has been limited research on the application of circular economy principles in the built environment, within a wholesystems context. Across Europe, most research and activity has focused on end-of-pipe solutions to manage waste generation (EC, 2011b; Yuan and Shen, 2011). This has led to overall improvement in the management of CDW (Defra, 2015).
However, much of this recovered waste is downcycled, where the value, quality and functionality are lower than the original product (Walsh, 2012).

The key aspects in applying circular economy across a building's life cycle, derived from the literature, are shown in Table 2. However, these aspects lack wide-scale adoption and are often applied in isolation either within a particular sector or project, with little consideration of the economic aspects across a building's life cycle. UKCG (2014) identified a key challenge of an unproven business case underpinned by viable business models such as requiring manufacturers to be responsible for their products once they reach their end of life. While this is evident in such sectors as medium-lived consumer products, it is largely absent in the built environment (EMF and MCK, 2014; Lacy et al., 2014; Pollard et al., 2016; Schulte, 2013). Other barriers include the lack of a holistic approach across the supply chain, short-term thinking and the low value of many construction products at the end of life (IC, 2015; Schult et al., 2015). Nevertheless, there are a few examples emerging on the application of circular economy principles, mainly related to material choice and design considerations (Kiser, 2016; Laubscher and Marinelli, 2014; Thornback and Adams, 2016).

\section{Research methodology}

The adopted methodology combined both a quantitative approach, in the form of an online survey and a qualitative approach, through an event convened by the government and industry Green Construction Board (GCB). The online survey was used to establish the construction industry's level of awareness of the circular economy and their view on the importance of the challenges and enablers for greater adoption. Some of the issues were replicated to allow comparison and analysis of any relationships. The survey was available for completion over a 2-month period and resulted in 110 valid responses. The sampling frame comprised construction industry associations, representing industry activities, consultants and researchers, building owners, manufacturers, designers and contractors. There were seven sections and a total of 18 questions. For every question, a four-point Likert scale was used to gauge the

Table 1. Circular economy principles (compiled from the main sources within the literature)

\begin{tabular}{lc} 
Principle & Source \\
\hline $\begin{array}{l}\text { Increasing the productivity of materials by doing the same or more with less } \\
\text { Eliminating waste by defining materials as either technical or biological nutrients }\end{array}$ & $\begin{array}{c}\text { Fuller (1973), Hawken et al. (1999), Lund (1955), } \\
\text { Stahel (2010), Womack et al. (1990) }\end{array}$ \\
enabling them to be within closed material loops; 'waste as food' & EMF (2013a, 2013b), Lyle (1994), McDonough and \\
Maintaining or increasing the value of materials, environmentally and economically & EMF (2013a, 2013b), Weizsäcker et al. (1997) \\
$\begin{array}{l}\text { Thinking in systems by studying the flows of material and energy through } \\
\text { industrialised systems, understanding the links, how they influence each other and } \\
\text { the consequences, enabling closed-loop processes where waste serves as an input }\end{array}$ & (2008), Pauli (2010)
\end{tabular}


Table 2. Circular economy aspects across a building's life cycle stage (developed from the main sources within the literature)

\begin{tabular}{|c|c|}
\hline Life cycle stage & Circular economy aspect \\
\hline Design & $\begin{array}{l}\text { DfD } \\
\text { Design for adaptability and flexibility } \\
\text { Design for standardisation } \\
\text { Design out waste } \\
\text { Design in modularity } \\
\text { Specify reclaimed materials } \\
\text { Specify recycled materials }\end{array}$ \\
\hline Manufacture and supply & $\begin{array}{l}\text { Eco-design principles } \\
\text { Use less materials/optimise material use } \\
\text { Use less hazardous materials } \\
\text { Increase the lifespan } \\
\text { Design for product disassembly } \\
\text { Design for product standardisation } \\
\text { Use secondary materials } \\
\text { Take-back schemes } \\
\text { Reverse logistics }\end{array}$ \\
\hline Construction & $\begin{array}{l}\text { Minimise waste } \\
\text { Procure reused materials } \\
\text { Procure recycled materials } \\
\text { Off-site construction }\end{array}$ \\
\hline In use and refurbishment & $\begin{array}{l}\text { Minimise waste } \\
\text { Minimal maintenance } \\
\text { Easy repair and upgrade } \\
\text { Adaptability } \\
\text { Flexibility }\end{array}$ \\
\hline End of life & $\begin{array}{l}\text { Deconstruction } \\
\text { Selective demolition } \\
\text { Reuse of products and components } \\
\text { Closed-loop recycling } \\
\text { Open-loop recycling }\end{array}$ \\
\hline \multicolumn{2}{|c|}{$\begin{array}{l}\text { All stages: management of information including metrics and } \\
\text { datasets }\end{array}$} \\
\hline
\end{tabular}

respondent's level of awareness and the relative importance of various challenges and enablers. An appropriate rating was provided from ' 1 ' - the lowest level to ' 4 ' - the highest level. Respondents could also give their qualitative views for each question. The Statistics Package for Social Science version 22 was used to analyse the quantitative data. This assisted in obtaining the overall mean response levels and any qualitative data were tabulated manually.

To ensure the participation of a wide range of stakeholders and to establish reasonable coverage, qualitative information was derived from a GCB event 'circular economy thinking challenges and opportunities for the construction sector', with 97 attendees (GCB, 2016). Breakout sessions were held to discuss the challenges and enablers in the adoption of the circular economy in the built environment, with $\sim 25$ attendees at each session. The analysis of these sessions has focused on exploring the key themes and trends complementing the findings of the online survey.

\section{Results}

The following section is subdivided into the respondent's profile, an analysis of the level of awareness derived from the online survey and an examination of the challenges and enablers resulting from the online survey and breakout sessions.

\subsection{Respondent's profile}

The questionnaire respondents comprised: researchers and consultants $(26 \%)$, contractors $(25 \%)$, clients $(14 \%)$, product manufacturers $(10 \%)$, demolition contractors $(10 \%)$ and designers $(7 \%)$. Other respondents included government representatives $(4 \%)$ and trade associations covering building products, reuse, flooring and concrete $(4 \%)$.

Over half of the survey respondents were from large organisations with an annual turnover of more than $£ 50$ million and more than 500 employees. The remaining respondents were distributed fairly evenly between small- (1-49 employees) and medium-sized organisations (50-500 employees). Of the event attendees, 58\% were from large companies with the remainder from small- and medium-sized companies. Of these, 73 and $60 \%$ of the respondents had more than 10 years of experience in construction and sustainability practice, respectively. For the event, the attendees were broadly representative of the construction industry comprising clients $(5 \%)$, designers $(9 \%)$, manufacturers $(10 \%)$, contractors $(23 \%)$, consultants $(30 \%)$, government representatives $(12 \%)$, and trade and professional associations ( $9 \%)$. Twenty-two of the attendees also participated in the online survey.

\subsection{Circular economy awareness}

The questionnaire respondents were asked to rank their level of awareness of the circular economy with ' 1 ' as unaware and ' 4 ' fully aware. The results are summarised in Figure 1. The respondents were largely aware of the circular economy (3.30), thought this diminished within their own organisation $(2 \cdot 71)$ and further still industrywide $(2 \cdot 16)$. In all cases, the level of awareness within the respondent's organisations was lower than their own. The manually tabulated responses indicate that while there is a good level of awareness, there is a clear need to articulate the benefits of the circular economy in a transparent and measurable manner; this was supported by the views from the breakout sessions particularly in regard to the business case.

The participating designers (2.09), clients (1.96) and subcontractors (1.63) were generally perceived to have a lower awareness than the rest of the respondents. This may have a negative impact on the uptake or a circular economy as a strong view emerged from the manually tabulated responses and the breakout sessions of the need for client buy-in and designers to be fully engaged. Manufacturers were considered to be the most aware $(2 \cdot 19)$; this could be due to the existing work of various material sector trade associations on sustainability. 


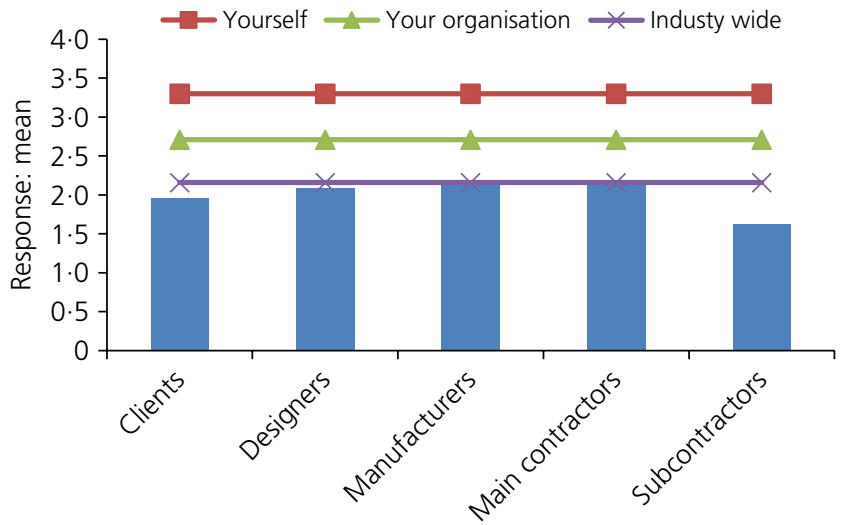

Figure 1. Levels of awareness for circular economy in the construction sector

An analysis by the type of organisation shows slightly different results with manufacturers, researchers and consultants rating designers with a high level of awareness. Conversely, demolition contractors thought designers to be the least aware. This is unsurprising as the demolition companies' deal with buildings which rarely have circularity designed in. Designers were also perceived to have a lack of knowledge on how to adopt circular economy principles, during the breakout sessions. The main contractors were the most varied with the demolition respondents ranking them with the highest awareness (2.45); however, designers reported that they had low awareness (1.75). These results may be partially explained by the level of relationship between sectors. Interestingly, most of the respondents viewed their sector as the most aware, except for clients, which could be due to a certain amount of bias.

\subsection{Challenges and enablers for the circular economy}

The survey respondents were asked to rank the significance of various challenges for adopting circular economy industrywide and the potential enablers (for challenges: ' 1 ' - insignificant, ' 4 ' - major challenge and for enablers: ' 1 ' - not important, '4' - very important). The challenges and enablers were subdivided into a number of categories, which are discussed in Sections 5.3.1-5.3.7. The breakout sessions focused on the applicability of business models, material flows, and recovery and design considerations.

The key challenges identified by the survey respondents for adopting circular economy industrywide are shown in Figure 2. The most significant challenge, which was ranked highly by all stakeholders, is the lack of an incentive to design for end-of-life issues for construction products (3.32). A number of economic challenges were also deemed the most significant including a lack of market mechanisms to aid greater recovery $(3 \cdot 26)$, the low value of products at end of life (3.06) and an unclear financial case (3.25). The construction industry's structure also was viewed to be a significant challenge in the form of a fragmented supply chain (3.15), as well as a perceived general lack of interest $(3 \cdot 12)$, awareness $(3 \cdot 11)$ and knowledge (3.03). Design considerations including the lack of consideration for end-of-life issues at a building level $(3 \cdot 19)$ and the complexity of buildings (3.23) were also thought to be significant challenges. This was broadly similar to those discussed in the breakout sessions, with financial, structural and knowledge all considered to be important issues.

The survey results for the circular economy enablers are shown in Figure 3. The most important is a clear business case (3.61) which was ranked the most significant by all stakeholders and as highly important in the breakout sessions with the need to understand the commercial viability. Enabling the recovery of materials through viable (logistically and commercially) takeback schemes (3.43), development of higher value markets (3.42) and enabling technologies (3.35) were all ranked as highly significant. An awareness raising campaign (3.24) and best practice case studies were also considered as very important (3.31) with the breakout sessions emphasising the need for delivery by example.

The following section provides an analysis of specific challenges and enablers by survey respondent type and from the breakout sessions.

\subsubsection{Legislation and policy}

While legislation and policy did not feature within the most significant challenges, ambiguous end-of-waste regulations was ranked as the largest legislation and policy challenge (2.91) with demolition contractors ranking it the highest $(3 \cdot 27)$. Having no circular economy-specific legislation in place was thought to be an important challenge (2.82) and an important enabler (3.00), although clients, designers and manufacturers thought it to be less important. This view was also echoed in the breakout sessions, although it was thought unlikely for specific legislation to be developed. Consequently, other incentives were suggested as important within the breakout sessions, such as planning requirements. Green public procurement requirements were also seen as an important enabler $(3 \cdot 10)$, especially by designers (3.57), and researchers and consultants $(3 \cdot 17)$. A challenge of most policy focused on landfill diversion $(2 \cdot 70)$ was suggested to be detrimental to reuse and during the breakout sessions it was noted that at a European level, a focus on recycling has in many cases led to downcycling.

\subsubsection{Awareness and understanding}

Limited awareness, interest and knowledge are identified as significant challenges. However, these views were not 


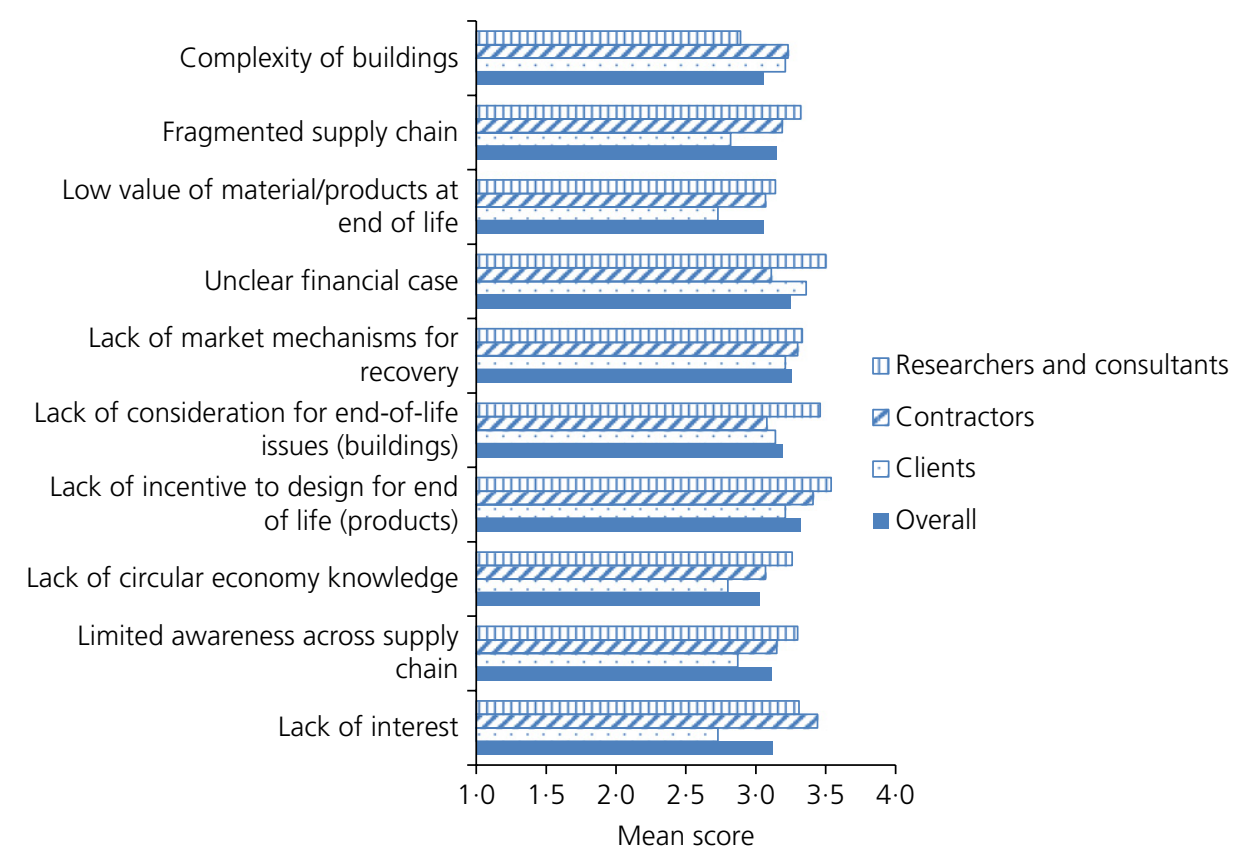

Figure 2. The most significant challenges for implementing circular economy industrywide

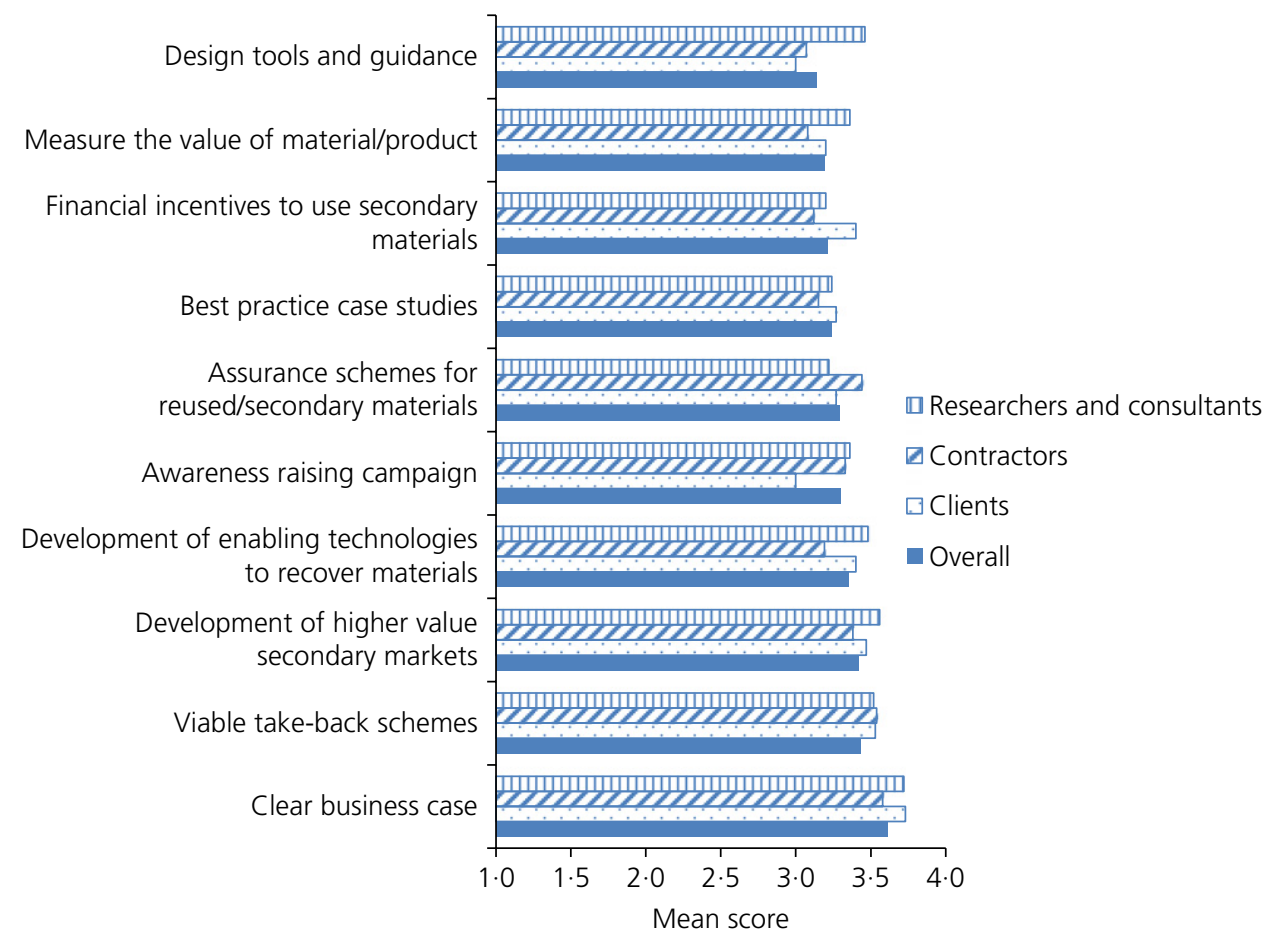

Figure 3. The most significant enablers for implementing circular economy industrywide 
represented throughout; client respondents ranked the challenges of lack of knowledge (2.80) and interest (2.73) as of medium significance as did manufacturers (2.55 and 2.64). Medium- and large-sized companies believed that the lack of knowledge was a greater challenge than smaller companies, although companies of all sizes believed that an awareness campaign would be an important enabler. Survey respondents with greater construction experience believed that a lack of interest was a highly significant challenge. A theme evident from the tabulated responses and the breakout sessions was a lack of clarity on what the circular economy actually entailed and the apparent confusion between terms such as reuse and recycling, suggesting that greater precision is required.

\subsubsection{Manufacture of construction products}

Designers (3.57) and researchers and consultants (3.54) ranked a lack of incentive to design products for end of life as the biggest challenge. This view was held regardless of the company size or length of experience. Having some form of producer responsibility for construction products was viewed as an important enabler, particularly by contractors $(3 \cdot 30)$ and demolition contractors $(3 \cdot 55)$. However, it was viewed as the least important enabler by manufacturers (2.27). A strong view from the breakout sessions was that due to the differences within the construction products sector and associated product lifespans, different types of approaches and solutions are needed; therefore such producer responsibility requirements may not be appropriate for products that remain in situ over a building's lifetime.

\subsubsection{Designing and operating buildings}

The lack of end-of-life considerations during a building's commissioning, design and construction was deemed to be a significant challenge by designers $(3 \cdot 50)$, researchers and consultants (3.46). A key issue noted in the breakout sessions was the uncertainty surrounding long-term user needs, with adaptability and flexibility being important aspects. From the tabulated results, a key theme was the importance of optimising the lifespan and the value of refurbishing to extend the life of buildings, resulting in less resource usage through more utilisation. The complexity of buildings was viewed as a major challenge particularly by clients $(3 \cdot 21)$ and a number of views from the breakout sessions were provided on moving towards more modularisation and simplification of design to counteract this. Overall, enablers such as a standard for DfD design tools and guidance were viewed as important ( $3 \cdot 02$ and $3 \cdot 14$, respectively), with designers rating these particularly highly important $(3 \cdot 43)$.

\subsubsection{Recovery of materials and products}

The lack of market mechanisms to aid recovery was ranked as one of the top challenges (3.26) by all of the stakeholders, which corresponds with the development of financial incentives to use secondary materials as an enabler (3.21). A number of the tabulated responses thought it important that the market volatility for secondary materials was addressed and the dependence of certain secondary materials on the marketplace. A theme emerging from the breakout sessions was how to ensure that the right quality and quality of secondary materials are available for reuse. Clients (2.50), manufacturers (2.45) and demolition contractors (2.36) ranked the issue of downcycling as low. This may link to a general lack of understanding of the circular economy, whereby the maintaining value is an important principle.

There was a general agreement from the tabulated responses that there is a current lack of knowledge of what can be done with products at the end of life. This was exemplified by one respondent stating 'there is a technical challenge of how a component designed 150 years ago can be envisaged to be reused' Linked to this were the challenges stated by a number of respondents of the insurance and warranty issues of using reused materials, especially in a structural capacity and the practicalities of finding time to enable this to happen. As such, assurance schemes for reused/secondary materials was ranked high as an enabler, especially by contractors (3.44) and demolition contractors $(3 \cdot 27)$. Unsurprisingly, contractors scored take-back schemes to be particularly high $(3 \cdot 54)$, with the tabulated responses suggesting that the current schemes were restrictive, while demolition contractors viewed the recovery of materials by way of markets (3.55) and technical advancements $(3 \cdot 55)$ as hugely significant.

\subsubsection{Business}

The fragmented supply chain was viewed as a key challenge by researchers and consultants (3.32) and contractors (3.14) with a number of survey respondents criticising the lack of a holistic approach; this was also echoed in the breakout sessions along with the competitive nature of the construction industry. Manufacturers and demolition contractors (2.73) viewed limited viable business models as less important than other stakeholders. Indeed, the development of leasing models was ranked as the least important enabler $(2 \cdot 68)$ by the majority of stakeholders and, particularly for demolition, (1.73) and manufacturers $(2 \cdot 36)$. Contracts based on performance/function was viewed as important by contractors $(3 \cdot 15)$ but less so for other stakeholders. Discussion from the breakout sessions questioned the value of these business models, especially for longer lived products. A view from the tabulated responses was of the risk of changing practices, in particular the time and cost implications and how any initial cost could be offset.

Information and metrics as enablers were viewed as important including providing information on circularity within the building information models (BIM), particularly by designers $(3 \cdot 14)$, contractors $(3 \cdot 07)$ and manufacturers $(3 \cdot 00)$. This may be because these stakeholders are likely to be familiar with 
BIM. The development of a decision-making framework across a building's life cycle was viewed as the most important business enabler for clients (3.00), designers (3.50), and for researchers and consultants (3.29). This could be due to these stakeholders having more of an interest in the life cycle's performance. A key finding from the breakout sessions was the need for a set of common circularity metrics across the building life cycle in order to understand the key opportunities. It was noted that the European standards (CEN TC 350 (AFNOR, 2016)) has a renewed focus on end-of life-issues, known within the formal construction life cycle as Module D.

\subsubsection{Economic}

One of the largest challenges for adopting circularity in the built environment is the unclear financial case, which ranked number one for the majority of stakeholders; having a clear business case was the most important enabler (3.61). The need to articulate the value aspects of the circular economy was viewed as paramount during the breakout sessions and the ability to measure the value of a product/material across its life cycle $(3 \cdot 19)$ was a significant enabler for designers $(3 \cdot 71)$ and clients (3.20). There was a common thread of the cost benefit for each party adopting the circular economy not being fully understood and a general perception that the initial investor may not benefit. Cost and associated profit was seen to be the dominant factor in any decision-making process which can be compounded by the short-termism of many clients. The challenge of low value of products/materials at the end of life was also significant for designers (3.43) and manufacturers (3.18), which can make take-back schemes and reprocessing uneconomical.

\section{Discussion}

Although there was a general awareness of the circular economy among the survey respondents and event attendees, there are a number of considerable economic, organisational and technical challenges that need to be overcome to enable wide-scale adoption. The following sections summarise these main themes from the survey and breakout sessions in the context of the literature and examines the implications of progressing towards a circular economy in the construction sector.

\subsection{The value element of the circular economy}

One of the key principles often quoted of the circular economy is to keep materials at a high value wherever possible (EMF, 2013a; SG, 2015; ZWE, 2016). However, there has been criticism of limited research in this area (Lieder and Rashid, 2015) and there is an underlying question on how to develop a clear economic case for circularity in the built environment. There is a large amount of uncertainty on material resource prices into the future (Morgan, 2014), resulting in the difficulty to predict the potential value of materials at the end of life, particularly for long-lived products. Additionally, many construction products at their end of life at today's prices are also low in value, making it uneconomical to reuse (Kay and Essex, 2012; Thornback, 2016). Keeping upfront costs low is still an issue in construction, which may negate any future value and it has been highlighted that the initial investor may not benefit directly, as the benefits may fall to the final owner (Zuidema, 2015). Therefore, a greater understanding of the cost benefit of applying circular economy principles to each party involved is required. While alternative business models have been explored in other sectors (Bocken et al., 2014; Lewandowski, 2016; Tukker, 2015), with Schult et al. (2015) questioning their viability for long-life structures, they lack research and application in the construction sector. How building and material assets are currently valued may also provide disincentives for their future use (Wallace and Raingold, 2012).

\subsection{Organisational issues}

Issues relating to the fragmented structure of the construction industry are commonly at the core when implementing new or different strategies (BIS, 2013). The research findings have shown that this is similar for applying circular economy principles with the respondents stating that a lack of holistic approach and the 'silo' approach of undertaking design, construction, facility management and end-of-life activities are the key challenges. This is compounded by the short-termism of some clients/developers (Bordass and Leaman, 2013). The lack of client awareness and the problem of the continuity of actors across a building's life cycle have been explored within the context of sustainable buildings (Häkkinen and Belloni, 2011). From a circular economy perspective, it is likely to make the establishment of the ownership of material flows within the built environment sector more difficult, which is an important ingredient for circularity. In addition, the benefits of adopting circular economy may not be shared equally across the supply chain. This is reflected in the survey findings with the major challenge of a lack of an incentive to design for end of life. While there has been research undertaken on improving the resource efficiency of construction products and their supply chains (AIS, 2012; Dunster, 2014; Hobbs and Ashford, 2013; Smith, 2013a, 2013b), there is less clarity on the activities each part of the construction sector can undertake to enable themselves and other parts to become more circular. It is likely that the application of the circular economy will vary depending on the circumstance of a project and its supply chain due to their diverse nature. This is where the circular economy principle of systems thinking is central, identifying where synergies and divergences lie and the potential for unintended or perverse consequences. Collaboration has been identified as a key requirement for progressing the circular economy (Chamberlin et al., 2013; Preston, 2012) and this should be explored within the procurement and supply chain management activities, as well as within the information sharing capabilities of BIM. 


\subsection{Technical issues}

To enable an increased circularity of materials at their highest possible value, technical challenges will need to be overcome (Geng and Doberstein, 2008). These challenges may present themselves at the material, product and/or building level. This is a principal issue for the existing building stock, which has not been designed for circularity (Wallace and Raingold, 2012). This may be intensified by the move towards more thermalefficient building stock, modern methods of construction and intelligent buildings, which may encourage the greater use of products that are more difficult to reuse and recover (Adams et al., 2013). To enable circularity, through an increase in the lifespan of buildings, the design should take into account adaptability and flexibility, as well as deconstruction at the end of life (Cheshire, 2016). While these aspects are continuing to be explored with a growing interest (Pinder et al., 2013), there is a shortage of knowledge of how the design of buildings, components and products can affect their circularity. However, this is likely to improve, with the concept of material passports starting to evolve, although this still is in its infancy (BAMB, 2016).

\section{Conclusions}

There is a significant body of literature on the drivers and benefits of circular economy; however, little research or widescale application has been undertaken within a construction context. Hence, this research sets out to provide an indication of the awareness levels of circular economy in the construction sector and presents the challenges for greater adoption and how these may be overcome through enabling factors. The research was undertaken through surveying the UK construction industry by way of an electronic survey and undertaking breakout sessions at an industry event. These two streams of activity intended to provide a representative picture of the larger companies operating across the industry.

The findings show that at an individual level, the majority of the survey respondents were aware of the circular economy concept. However, at an industrywide level there was a lack of awareness. The absence of a broad consensus of what the circular economy looks like in the built environment could be a contributing factor to this. This perceived lack of industrywide awareness, supported by the survey and breakout session findings that parts of the supply chain, such as clients and designers, have little knowledge on how to adopt circular economy principles is likely to impede uptake of circularity in the short term. The most significant challenges identified by the survey were a lack of incentive to design for end-of-life issues, followed by the lack of market mechanisms to aid greater recovery and an unclear financial case. These challenges, combined with the fragmented nature of the construction industry (which was also rated significant), suggest that further incentives are required to enable a transition to a circular economy. Indeed, a clear business case was ranked the most important enabler by all stakeholders, with commercial viability identified in the breakout sessions as fundamental to shift current practices. Technical challenges including the lack of recovery routes and the complex design of buildings, whilst significant, are likely to be overcome to some extent through further research on enabling technologies and sharing of knowledge. A larger obstacle is the existing stock of buildings and infrastructure where circularity principles have not been adopted. That said, there are many opportunities to advance the circular economy through the enabling factors identified. Ones that ranked highly significant include the greater recovery of materials through viable take-back schemes and higher value markets, assurance schemes for reused materials, best practice exemplar case studies and an awareness scheme.

This research will contribute to a much needed debate within the construction industry supply chain to better engage with, understand and prioritise the key issues influencing the formulation and implementation of informed circular economy strategies. The research findings will be used to inform the next piece of research, to develop a framework for applying circular economy to buildings overcoming key economic, technical and organisational challenges.

\section{Acknowledgements}

This paper was based on research conducted within a research project 'Embedding Circular Economy in the Built Environment' funded by the BRE Trust. The authors acknowledge all those who participated in the questionnaire survey and the workshop event. Thanks are extended to the Green Construction Board Circular Economy Working Group and sponsors of the workshop event: BRE Trust, Construction Products Association and the Knowledge Transfer Network

\section{REFERENCES}

Adams K, Hobbs G and Yapp C (2013) Dealing with Difficult Demolition Wastes. IHS BRE Press, Watford, UK

AFNOR (2016) CEN/TC 350 - Sustainability of construction works. AFNOR Normalisation. See http://portailgroupe.afnor.fr/public espacenormalisation/centc350/index.html (accessed 13/02/2017).

AIS (Association of Interior Specialists) (2012) Mineral Wood Ceiling Tiles: A Resource Efficiency Action Plan. AIS, Birmingham, UK.

Allwood JM, Ashby MF, Gutowski TG and Worell E (2011) Material efficiency: a white paper. Resources, Conservation and Recycling 55(3): 362-381

BAMB (Building As Material Banks) (2016) Home - BAMB. BAMB, Brussels, Belgium. See http://www.bamb2020.eu/ (accessed 24/06/2016).

Behrens A, Giljum S, Kovanda J and Niza S (2007) The material basis of the global economy. Worldwide patterns of natural resource extraction and their implications for sustainable resource use policies. Ecological Economics 64(2): 444-453. 
Benton D (2015) Circular Economy Scotland. Green Alliance, London, UK.

Benton D and Hazell J (2013) Resource Resilient UK: A Report from the Circular Economy Task Force. Green Alliance, London, UK.

Benton D, Coats E and Hazell J (2015) A Circular Economy for Smart Devices. Green Alliance, London, UK.

BIS (Department for Business, Innovation and Skills) (2013) Supply Chain Analysis into the Construction Industry, A Report for the Construction Industrial Strategy. BIS, London, UK.

Bilitewski B (2012) The circular economy and its risks. Waste Management 32(1): 1-2.

Bocken NMP, Short SW, Rana P and Evans S (2014) A literature and practice review to develop sustainable business model archetypes. Journal of Cleaner Production 65: 42-56.

Bordass B and Leaman A (2013) A new professionalism: remedy or fantasy? Building Research and Information 41(1): 1-7.

Brandt S (1994) How Buildings Learn: What Happens After They're Built. Viking, New York, NY, USA.

Bullen P (2007) Adaptive reuse and sustainability of commercial buildings. Facilities 25(1/2): 20-31.

Chamberlin L, Jasmin E and Raskit A (2013) Wales and the Circular Economy: Favourable System Conditions and Economic Opportunities. WRAP, Banbury, UK.

Cheshire D (2016) Building Revolutions: Applying the Circular Economy to the Built Environment. RIBA Publishing, London, UK

Cossu R and Williams ID (2015) Urban mining: concepts, terminology, challenges. Waste Management 45: 1-3.

CPA (Construction Products Association) (2016) A Knowledge Resource for Circular Economy Thinking in Construction. Construction Products Association, London, UK. See http://www. constructionproducts.org.uk/news-media-events/blog/2016/ february/a-knowledge-resource-for-circular-economy-thinking-inconstruction/ (accessed 22/04/2016).

CRWP (Construction and Wastes Resources Platform) (2008) BigRec Survey - A Survey of the UK Reclamation and Salvage Trade. CRWP, Watford, UK.

Defra (2012) Resource Security Action Plan: Making the Most of Valuable Materials. Defra, London, UK.

Defra (2015) UK Statistics on Waste. Defra, London, UK

Dunster A (2014) Ready-Mixed Concrete: A Resource Efficiency Action Plan. British Ready Mixed-Concrete Association, London, UK.

Durmisevic E and Yeang K (2009) Designing for disassembly (DfD). Architectural Design 79(6): 134-137.

EC (European Commission) (2011a) Roadmap to a Resource Efficient Europe COM/2011/0571 Final. European Commission, Brussels, Belgium.

EC (2011b) Supporting Environmentally Sound Decisions for Construction and Demolition ( $C \& D)$ Waste Management - $A$ Practical Guide to Life Cycle Thinking ( $L C T$ ) and Life Cycle Assessment (LCA). JRC Scientific and Technical Reports. European Commission, Brussels, Belgium.

EC (2014) Resource Efficiency Opportunities in the Building Sector COM/2014/0445 Final. European Commission, Brussels, Belgium.

EC (2015) Closing the Loop - An EU Action Plan for the Circular Economy COM(2015) 614 Annex 1. European Commission, Brussels, Belgium.

Ecorys (2012) Mapping Resource Prices: The Past and the Future. Ecorys, Rotterdam, the Netherlands.

Ecorys (2014) Resource Efficiency in the Building Sector. Ecorys, Rotterdam, the Netherlands.

EEA (European Environment Agency) (2016) Circular Economy in Europe Developing the Knowledge Base. European Environment Agency, Copenhagen, Denmark, EEA Report No. 2/2016.
EMF (Ellen MacArthur Foundation) (2013a) Towards the Circular Economy: Economy and Business Rationale for Accelerated Transition. Ellen MacArthur Foundation, Cowes, UK.

EMF (2013b) Towards the Circular Economy: Opportunities for the Consumer Goods Sector. Ellen MacArthur Foundation, Cowes, UK.

EMF (2015) Growth Within: A Circular Economy Vision for a Competitive Europe. Ellen MacArthur Foundation, Cowes, UK.

EMF and MCK (Ellen MacArthur Foundation and McKinsey \& Company) (2014) Towards the Circular Economy: Accelerating the Scale-Up Across Global Supply Chains. World Economic Forum, Cologny, Switzerland.

Eurostat (2015) Construction Statistics - NACE Rev. 2. Eurostat, Luxembourg, Luxembourg. See http://ec.europa.eu/eurostat/ statistics-explained/index.php/Construction_statistics _ NACE Rev._2 (accessed 23/05/2016).

Eurostat (2016) Waste Statistics. Eurostat, Luxembourg, Luxembourg. See http://ec.europa.eu/eurostat/statistics-explained/index.php/ Waste_statistics (accessed 20/05/2016).

Fuller BR (1973) Nine Chains to the Moon: An Adventure Story of Thought. Jonathan Cape, London, UK.

GCB (Green Construction Board) (2016) Circular Economy Thinking \#CEThinking Live Blog - Challenges and Opportunities for the Construction Sector. Green Construction Board, London, UK. See http://www.greenconstructionboard.org/index.php/2012-0905-09-17-39/item/2370-circular-economy-thinking-cethinkingchallenges-and-opportunities-for-the-construction-sector (accessed 22/05/2016).

Geng $Y$ and Doberstein B (2008) Developing the circular economy in China: challenges and opportunities for achieving 'leapfrog development'. International Journal of Sustainable Development and World Ecology 15(3): 231-239.

Geng Y, Fu J, Sarkis J and Xue B (2012) Towards a national circular economy indicator system in China: an evaluation and critical analysis. Journal of Cleaner Production 23(1): 216-224.

Graedel T and Allenby B (1995) Industrial Ecology. Englewood Cliffs, Prentice Hall, NJ, USA.

Häkkinen T and Belloni K (2011) Barriers and drivers for sustainable building. Building Research and Information 39(3): 239-255.

Hawken P, Lovins A and Lovins L (1999) Natural Capitalism. Little, Brown and Company, Boston, MA, USA.

Hobbs G and Ashford P (2013) Foam Resource Efficiency Partnership: A Resource Efficiency Action Plan. Foam Resource Efficiency Partnership, Watford, UK.

IC (Imperial College) (2015) Business Models and Enablers for the Circular Economy in the Built Environment. Imperial College, London, UK.

ISWA (International Solid Waste Association) (2015) Circular Economy: Resources and Opportunities. International Solid Waste Association, Vienna, Austria.

Kay T and Essex J (2012) Pushing Reuse - Towards a Low Carbon Construction Industry. BioRegional, Wallington, UK.

Kibert CJ (2003) Deconstruction: the start of a sustainable materials strategy for the built environment. UNEP Industry and Environment 26(2-3): 84-88.

Kiser B (2016) Getting the circulation going. Nature 531: 443-446.

Lacy P, Keeble J, Robert M and Jacob R (2014) Circular Advantage. Accenture, Chicago, IL, USA, Report No. 14-3357.

Laubscher M and Marinelli T (2014) Integration of circular economy in business. In Proceedings of the 10th Conference: Going GreenCARE INNOVATION 2014, Vienna, UK. International CARE Electronics Office, Vienna, Austria.

Lewandowski M (2016) Designing the business models for circular economy - towards the conceptual framework. Sustainability 8(1): 43 . 
Lieder M and Rashid A (2015) Towards circular economy implementation: a comprehensive review in context of manufacturing industry. Journal of Cleaner Production 115: 36-51.

Lund RT (1955) 'Making Products Live Longer' a Paper for the Environment Directorate of the Organization of Economic Cooperation and Development. Massachusetts Institute of Technology, Cambridge, MA, USA.

LWARB (London Waste and Recycling Board) (2015) London - The Circular Economy Capital. London Waste and Recycling Board, London, UK.

Lyle J (1994) Regenerative Design for Sustainable Development. John Wiley, New York, NY, USA.

McDonough W and Braungart M (2002) Cradle to Cradle. North Point Press, New York, NY, USA.

McKinsey Global Institute (2011) Resource Revolution: Meeting the World's Energy, Materials, Food and Water Needs. McKinsey and Company, New York, NY, USA.

Meadows D and Wright D (2008) Thinking in Systems - A Primer. Chelsea Green Publishing, White River Junction, VT, USA.

Morgan J (2014) The Great Resource Price Shock. Green Alliance, London, UK.

Morgan J and Mitchell P (2015) Employment and the Circular Economy Job Creation in a More Resource Efficient Britain. Green Alliance and WRAP, London, UK.

MPA (Mineral Products Association) (2016) Mineral Products Association - Press Release 2015. Mineral Products Association, London, UK. See http://www.mineralproducts.org/16-release11. htm (accessed 22/06/2016).

Nasr N (2013) The circular economy is going global. Industrial Engineer 45(9): 22.

Osmani M, Price A and Glass J (2006) Architect and contractor attitudes to waste minimisation. Proceedings of the Institution of Civil Engineers - Waste and Resource Management 159(2): 65-72, https://doi.org/10.1680/warm.2006.159.2.65

Pauli G (2010) The Blue Economy: 10 Years - 100 Innovations 100 Million, Report to the Club of Rome. Paradigm Publications, Taos, NM, USA.

Pinder J, Schmidt R III and Saker J (2013) Stakeholder perspectives on developing more adaptable buildings. Construction Management and Economics 31(5): 440-459.

Pollard S, Turney A, Charley F and Webster K (2016) The circular economy - a reappraisal of the 'stuff' we love. Geography 101: $17-28$.

Pratt K and Lenaghan M (2015) The Carbon Impacts of the Circular Economy Summary Report. Zero Waste Scotland, Stirling, UK.

Preston F (2012) A Global Redesign? Shaping the Circular Economy. Energy, Environment and Resource Governance. Chatham House, London, UK

Schulte UG (2013) New business models for a radical change in resource efficiency. Environmental Innovation and Societal Transitions 9: 43-47.

Schult E, Crielaard M and Mesman M (2015) Circular Economy in the Dutch Construction Sector. Rijkswaterstaat - Water Verkeer en Leefomgeving and National Institute for Public Health and the Environment (RIVM), Hague, the Netherlands, RIVM Report 2016-0024.

SG (Scottish Government) (2015) Making Things Last. Consultation on Creating a More Circular Economy in Scotland. Scottish Government, Edinburgh, UK

SG (2016) A Circular Economy Strategy for Scotland. Scottish Government, Edinburgh, UK.
Smith A (2013a) Clay Bricks and Clay Blocks Resource Efficiency Action Plan. Brick Development Association, London, UK.

Smith A (2013b) Precast Concrete: A Resource Efficiency Action Plan. Mineral Products Association, London, UK.

Stahel WR (2010) The Performance Economy. Palgrave Macmillan, Basingstoke, UK.

Stahel WR (2016) The business angle of a circular economy. Higher competitiveness, higher resource scarcity and material efficiency. In A New Dynamic: Effective Business in a Circular Economy (Webster K, Bleriot J and Johnson C (eds)). Ellen MacArthur Foundation, Cowes, UK, pp. 45-60.

Thornback J (2016) Circular Economy Thinking in Construction: A View from UK Manufacturers. Construction Products Association, London, UK. See http://www.constructionproducts.org. uk/media/87907/cpa-circular-economy-thinking-the-role-ofmanufacturers-12-february-2016.pdf (accessed 22/05/2016).

Thornback J and Adams K (2016) Knowledge Resource for Circular Economy Thinking in Construction. Green Construction Board, London, UK. See http://www.greenconstructionboard. org/images/stories $/ 112212 \% 20 \mathrm{GCB} \% 20$ Circular $\% 20$ Economy $\%$ 20April\%202016\%20v3.pdf (accessed 22/05/2016).

Tingley D (2012) Design for Deconstruction: An Appraisal. PhD thesis, The University of Sheffield, Sheffield, UK.

Tukker A (2015) Product services for a resource-efficient and circular economy - a review. Journal of Cleaner Production 97: $76-91$.

UKCG (UK Contractors Group) (2014) Circular Economy. UK Contractors Group, London, UK. See http://www.wrap.org. uk/sites/files/wrap/WRAP $\% 20$ Built $\% 20$ Environment $\% 20-\%$ 20Circular\%20Economy\%20Jan\%202013.pdf (accessed 22/05/2016).

Wallace S and Raingold A (2012) Resilience in the Round. Aldersgate Group, London, UK.

Walsh B (2012) Standards, Module L2m4-1 in WR1403 - Business Waste Prevention Evidence Review. Defra, London, UK.

WEF (World Economic Forum) (2015) Project MainStream - A Global Collaboration to Accelerate the Transition Towards the Circular Economy Status Update. World Economic Forum, Geneva, Switzerland.

Weizsäcker E, Lovins A and Lovins L (1997) Factor Four. Earthscan, London, UK.

Womack JP, Jones DT and Roos D (1990) The Machine that Changed the World. Free Press, New York, NY, USA

WRAP (Waste Resources Action Programme) (2016) WRAP and the Circular Economy. Waste Resources Action Programme, Banbury, UK. See http://www.wrap.org.uk/about-us/about/wrap-andcircular-economy (accessed 11/05/2016).

Yuan $\mathrm{H}$ and Shen $\mathrm{L}$ (2011) Trend of the research on construction and demolition waste management. Waste Management 31(4): 670-679.

Zuidema R (2015) Material Value and Reuse? The End-User Couldn't Care Less. Or Otherwise? - BRIQS Fit-Out Mastery. BRIQS, Amsterdam, the Netherlands. See http://www.briqs. org/material-value-and-reuse-the-end-user-couldnt-care-less/ (accessed 24/06/2016).

ZWE (Zero Waste Europe) (2016) Circular Economy, Zero Waste Europe. Zero Waste Europe, Brussels, Belgium. See http://www. zerowasteeurope.eu/category/waste/circular-economy/ (accessed 24/06/2016)

ZWS (Zero Waste Scotland) (2015) Circular Economy Thinking and Action at the University of Edinburgh. Zero Waste Scotland, Stirling, UK. 